\title{
Improved step length symmetry and decreased low back pain with the use of a rocking-soled shoe in a patient with unilateral hallux rigidus
}

\author{
Jeffrey Cusack, ${ }^{1}$ Garry Shtofmakher, ${ }^{2}$ Roger Lee Kilfoil Jr, ${ }^{2}$ Steven $\mathrm{Vu}^{2}$
}

${ }^{1}$ Department of Orthopedics and Pediatrics, New York College of Podiatric Medicine, New York, New York, USA ${ }^{2}$ New York College of Podiatric Medicine, New York, New York, USA

\section{Correspondence to}

Garry Shtofmakher, gshtofmakher@nycpm.edu

Accepted 18 August 2014
CrossMark

To cite: Cusack J,
Shtofmakher G, Kilfoil RL,
et al. BMJ Case Rep
Published online: [please
include Day Month Year]
doi:10.1136/bcr-2014-
206408

\section{DESCRIPTION}

A 53-year-old African-American man presented to a local podiatry outpatient clinic with a chief symptom of unilateral pain in the first metatarsophalangeal joint (MTPJ) of his left foot as well as a secondary concern of chronic low back (lumbosacral) pain. He stated that the onset of the foot pain several years ago was insidious, but has been gradually increasing in intensity. He stated that the foot pain was proportionate to the amount and speed of ambulation, and was decreased with non-weightbearing. He also related that he noticed that the foot pain was also somewhat lessened if he 'slowed down', and took shorter steps. He stated that he had tried several types of corrective foot orthotic devices, both over the counter and custom made, none of which provided any significant relief. With regard to his back pain, the patient reported that he was told by his chiropractic physician that he had 'arthritis' at the L4-L5 disc level. The patient stated that his back pain also was not the result of any precipitating trauma, but rather seemed to have increased over the years. He denied any sciatic

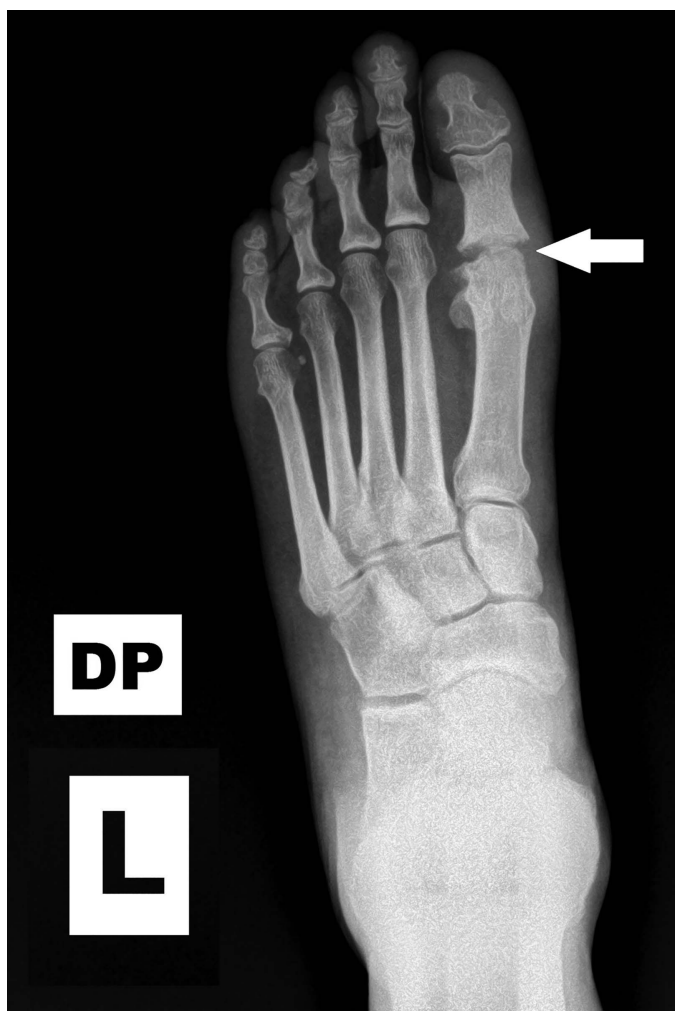

Figure 1 Dorsoplantar radiograph of the left foot: arrow reveals degenerative changes at the first metatarsophalangeal joint.

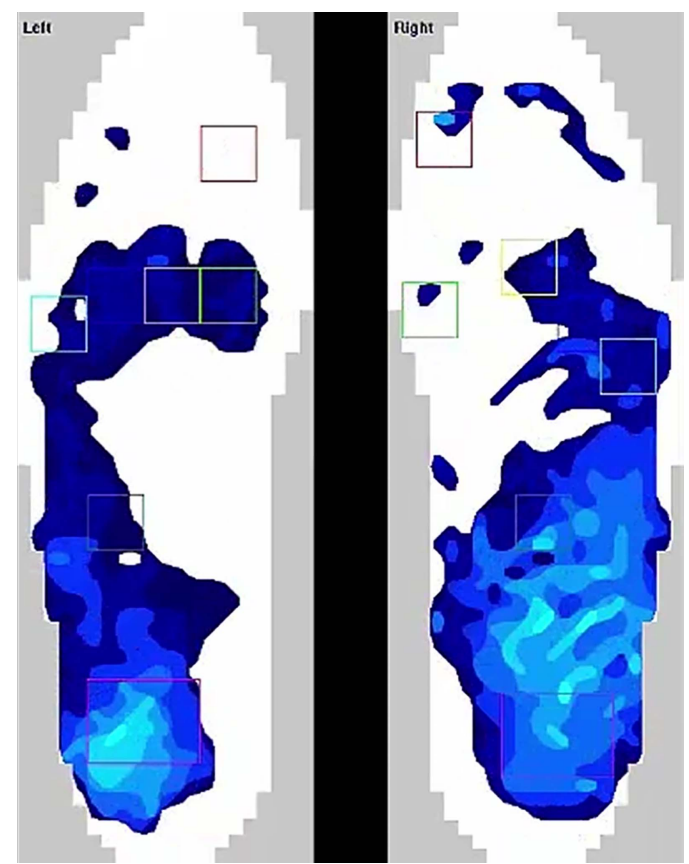

Video 1 Baseline in-shoe pressure and timing analysis (F-Scan) revealed a planus foot, with a complete arthrodesis of the left first MTPJ. In-Shoe pressure and timing analysis with the patient wearing rocking-soled shoes reveals markedly increased active propulsion on the left.

radiation of pain. While surgery was offered as an option for his foot pain, the patient declined and was seeking any possible non-surgical options.

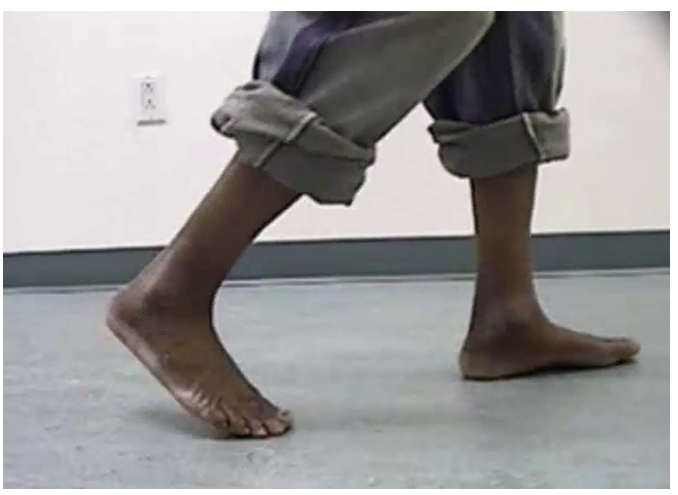

Video 2 Video gait analysis with the patient barefoot reveals a decreased step length on toe-off of the left foot when compared with toe-off of the right. There is decreased time in the propulsive phase of gait, a decreased stride length, and a decreased dorsiflexory range of motion at the left MTPJ. 


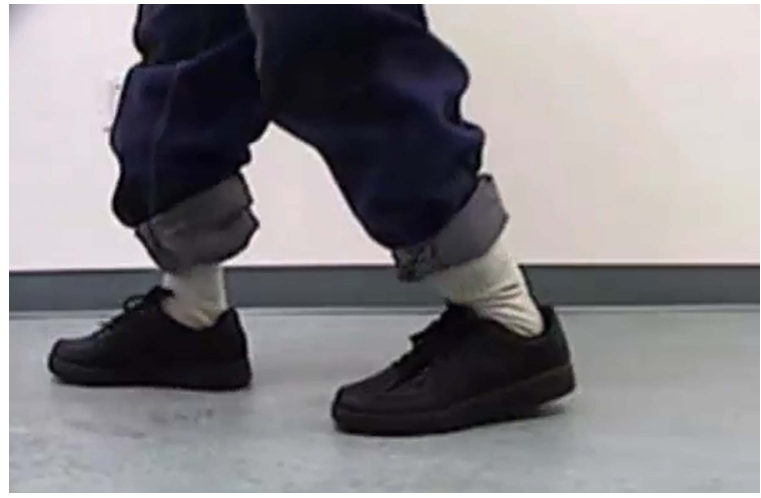

Video 3 Video Gait analysis of the patient in a flat soled shoe reveals a decreased step length in both the left and right lower extremities.

Physical examination, which included a static examination, radiographs (figure 1), video gait analysis (barefoot, in a flat-soled and rocking-soled shoe), in-shoe pressure and timing analysis (video 1), revealed a planus foot, with a complete arthrodesis of the left first MTPJ. There was a decreased step length on toe-off of the left foot when compared with toe-off of the right (video 2). A set of flat-soled shoes was then given to the patient to wear as a control. The stiff sole shortened the step length of the left and



Heel Rocker

Forefoot Rocker

Figure 2 An example of an MBT (Masai Barefoot Technology) brand rocking bottom shoe. Note the heel-rocker, forefoot-rocker and location where the first metatarsophalangeal joint is housed. Reprinted from Romkes et al, ${ }^{5}$ with permission from Elsevier.

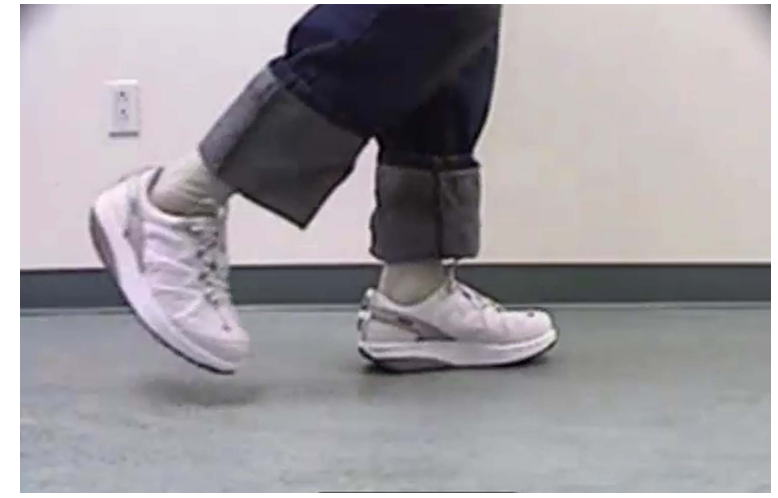

Video 4 Video gait analysis of the patient wearing rocking-soled shoes. Note the improved step length and improved symmetry of the patient's gait. There is increased velocity, and improved forefoot loading in propulsion.

right foot (video 3). The patient was then given a pair of rockingsoled shoes (figure 2) and asked to walk. Subsequently an immediate increase in step length of the left foot was observed (video 4). An improved symmetry was noted between the step length of the left and right foot. The active propulsion of the left foot markedly increased when the patient was wearing rocking-soled shoes (table 1).

Hallux limitus and the end-stage consequence, hallux rigidus is a condition that ultimately inhibits dorsiflexion at the first MTPJ. During the active propulsive phase, also known as terminal stance, simultaneous dorsiflexion at the MTPJ's as the heel lifts from the ground is crucial to enable maximum forward movement of the swinging limb. ${ }^{1}$ This permits the storage and ultimate release of stored elastic energy through the gluteal region, thereby minimising the amount of input from the iliacus and psoas muscles as the stance limb begins to leave the ground. ${ }^{2}{ }^{3}$ If pivotal movement at the first MTPJ is blocked, increased hip and knee flexion is only one of several compensatory mechanisms employed. Unfortunately this places an increased strain just below the origin of the psoas muscle in particular, resulting in an abnormal torque at the L4-L5 disc level. ${ }^{4}$

The rocking-shoe, by virtue of its ergonomically-engineered rocking platform, enables the wearer to artificially enhance their structurally-limited step length, as the first MTPJ can remain neutral while the shoe permits 'extension' across the forefoot. The improvement in step length once again enables the wearer to develop adequate hip extension, enabling the storage of energy which can then be released as elastic recoil. Clinically, the patient reported a reduction in foot as well as back pain (as noted in an analogue reporting chart) from a ' 10 ' to a ' 3 ' level. 
Table 1 Baseline timing analysis module of F-scan verses the rocking-soled shoe timing analysis module of F-scan

\begin{tabular}{|c|c|c|c|c|c|c|c|}
\hline Parameter & Normal range & Average & Left foot variation & SD & Average & Right foot variation & SD \\
\hline \multicolumn{8}{|c|}{ Baseline F-scan measurements } \\
\hline Contact & $14-20$ & 18 & $14-20$ & 2 & 19 & $18-20$ & 1 \\
\hline Foot flat & $16-22$ & 30 & $20-59$ & 15 & 51 & $27-67$ & 15 \\
\hline Midstance & $29-37$ & 60 & $49-86$ & 13 & 39 & $22-64$ & 16 \\
\hline Propulsive & $45-55$ & 22 & $0-31$ & 11 & 42 & $18-59$ & 16 \\
\hline$\rightarrow$ Active propulsive & $31-35$ & 0 & $-36-11$ & 18 & 24 & $5-41$ & 15 \\
\hline Passive propulsive & $14-20$ & 16 & $0-20$ & 8 & 18 & $13-20$ & 3 \\
\hline Single support & $60-72$ & 59 & $49-63$ & 5 & 63 & $60-69$ & 3 \\
\hline Total double support & $28-40$ & 41 & $37-51$ & 5 & 37 & $31-40$ & 3 \\
\hline Initial double support & $14-20$ & 18 & $14-20$ & 2 & 19 & $18-20$ & 1 \\
\hline Terminal double support & $14-20$ & 23 & $19-37$ & 7 & 18 & $13-20$ & 3 \\
\hline \multicolumn{8}{|c|}{ Rocking-soled F-scan measurements } \\
\hline Contact & $14-20$ & 15 & $13-18$ & 2 & 20 & $19-22$ & 1 \\
\hline Foot flat & $16-22$ & 26 & $23-29$ & 2 & 51 & $31-75$ & 14 \\
\hline Midstance & $29-37$ & 38 & $31-48$ & 7 & 39 & $29-58$ & 11 \\
\hline Propulsive & $45-55$ & 47 & $36-54$ & 7 & 40 & $19-51$ & 12 \\
\hline$\rightarrow$ Active propulsive & $31-35$ & 25 & $15-31$ & 6 & 26 & $6-40$ & 12 \\
\hline Passive propulsive & $14-20$ & 22 & $21-24$ & 1 & 15 & $11-18$ & 2 \\
\hline Single support & $60-72$ & 63 & $62-65$ & 1 & 65 & $62-69$ & 2 \\
\hline Total double support & $28-40$ & 37 & $35-38$ & 1 & 35 & $31-38$ & 2 \\
\hline Initial double support & $14-20$ & 15 & $13-18$ & 2 & 20 & $19-22$ & 1 \\
\hline Terminal double support & $14-20$ & 22 & $21-24$ & 1 & 15 & $11-18$ & 2 \\
\hline
\end{tabular}

\section{Learning points}

Patient consent Obtained.

Provenance and peer review Not commissioned; externally peer reviewed.

- Hallux limitus/rigidus can have a profound adverse effect on not only the foot, but the entire superstructure.

- The use of a rocking-soled shoe can artificially replace lost metatarsophalangeal joint movement and offers a practical, non-surgical approach to this commonly encountered condition.

- Hallux limitus/rigidus can be visualized radiographically by the presence of dorsal exostoses, joint space narrowing, and metatarsal head flattening. These radiographic changes indicate degenerative changes at the 1 st metatarsophalangeal joint.

\section{REFERENCES}

1 Scherer PR, Sanders J, Eldredge DE. Effect of functional foot orthoses on first metatarsophalangeal joint dorsiflexion in stance and gait. J Am Podiatr Med Assoc 2006;96:474-81.

2 Dananberg HJ. Gait style as an etiology to chronic postural pain. Part I. Functional hallux limitus. J Am Podiatr Med Assoc 1993;83:433-41.

3 Dananberg HJ. Gait style as an etiology to chronic postural pain. Part II. Postural compensatory process. J Am Podiatr Med Assoc 1993;83:615-24.

4 Hall C, Nester CJ. Sagittal plane compensations for artificially induced limitation of the first metatarsophalangeal joint: a preliminary study. I Am Podiatr Med Assoc 2004;94:269-74.

5 Romkes J, Rudmann C, Brunner R. Changes in gait and EMG when walking with the Masai Barefoot Technique. Clin Biomech (Bristol, Avon) 2006;(1):75-81.

Copyright 2014 BMJ Publishing Group. All rights reserved. For permission to reuse any of this content visit

http://group.bmj.com/group/rights-licensing/permissions.

BMJ Case Report Fellows may re-use this article for personal use and teaching without any further permission.

Become a Fellow of BMJ Case Reports today and you can:

- Submit as many cases as you like

- Enjoy fast sympathetic peer review and rapid publication of accepted articles

- Access all the published articles

- Re-use any of the published material for personal use and teaching without further permission

For information on Institutional Fellowships contact consortiasales@bmjgroup.com

Visit casereports.bmj.com for more articles like this and to become a Fellow 